\title{
Situação epidemiológica da brucelose bovina no Distrito Federal
}

\author{
[Epidemiological status of bovine brucellosis in the Federal District, Brazil]
}

\author{
V.S.P. Gonçalves ${ }^{1}$, L.A. Ribeiro ${ }^{2}$, R.A. Caldas $^{1}$, P.F.C. Francisco ${ }^{1}$, R.A. Dias ${ }^{3}$, F. Ferreira ${ }^{3}$, \\ M. Amaku ${ }^{3}$, J.S. Ferreira Neto ${ }^{3}$, V.C.F. Figueiredo ${ }^{4}$, J.R. Lôbo ${ }^{4}$, J.R.J. Borges ${ }^{1}$ \\ ${ }^{1}$ Faculdade de Agronomia e Medicina Veterinária - UnB \\ Caixa Postal 4508 \\ 70910-970 - Brasília, DF \\ ${ }^{2}$ Secretaria de Estado de Agricultura e Pecuária do Distrito Federal - Brasília, DF \\ ${ }^{3}$ Faculdade de Medicina Veterinária e Zootecnia - USP - São Paulo, SP \\ ${ }^{4}$ Departamento de Saúde Animal - MAPA - Brasília, DF
}

\begin{abstract}
RESUMO
Realizou-se um estudo para caracterizar a situação epidemiológica da brucelose bovina no Distrito Federal (DF). No total foram amostrados 2.019 animais, provenientes de 278 propriedades. Em cada propriedade visitada aplicou-se um questionário epidemiológico para verificar o tipo de exploração e as práticas de criação e sanitárias que poderiam estar associadas ao risco de infecção pela doença. $\mathrm{O}$ protocolo utilizado foi o da triagem com o teste do antígeno acidificado tamponado e a confirmação dos positivos com o teste do 2-mercaptoetanol. O rebanho foi considerado positivo quando pelo menos um animal foi reagente às duas provas sorológicas. A prevalência no DF foi de 2,5\% [1,0-5,1\%] para propriedades e de $0,16 \%$ [0,04-0,28\%] para animais. Em razão dos resultados encontrados, que permitem pensar em estratégias de erradicação, recomenda-se que o DF intensifique o diagnóstico de brucelose, tanto na forma de testes sorológicos sistemáticos como pela introdução de mecanismos de detecção rápida em laticínios, em ambos os casos a fim de aumentar o número de propriedades certificadas como livres da doença e melhorar a sensibilidade do sistema de vigilância ativa.
\end{abstract}

Palavras-chave: bovino, brucelose, prevalência, Distrito Federal

\begin{abstract}
A study to characterize the epidemiological status of brucellosis was carried out in the Federal District of Brazil. A total of 2,019 serum samples from 278 herds were collected. In each herd, it was applied an epidemiological questionnaire focused on herd traits as well as husbandry and sanitary practices that could be associated with the risk of infection. The serum samples were screened for antibodies against Brucella spp. by the Rose-Bengal Test (RBT), and all positive sera were re-tested by the 2mercaptoethanol test (2-ME). The herd was considered positive if at least one animal was positive on both RBT and 2-ME tests. Herd prevalence was estimated as 2.5\% [1.0-5.1\%] whereas animal prevalence was $0.16 \%$ [0.04-0.28\%]. Given these results, that may warrant the implementation of eradication strategies, there is a case for intensifying the serological testing in the Federal District, coupled with the introduction of rapid detection methods by the dairy industries, with a view to increasing the number of accredited free herds and improving the sensitivity of the surveillance system..
\end{abstract}

Keywords: cattle, brucellosis, prevalence, Federal District, Brazil

Recebido em 27 de março de 2009

Aceito em 23 de setembro de 2009

E-mail: vitorspg@unb.br 


\section{INTRODUÇÃO}

O Distrito Federal (DF), localizado na região Centro-Oeste do País, ocupa uma área territorial de $5.801,937 \mathrm{~km}^{2}$. Seu efetivo bovino foi calculado em 98.740 animais, o que corresponde a aproximadamente $0,1 \%$ do rebanho da região Centro-Oeste, e tem-se mantido estável. Embora a produção de animais esteja em ascensão, o DF está mais voltado para a lavoura, pois a utilização das terras para esse fim cresceu mais de $180 \%$, enquanto o tamanho de áreas reservadas para pastagens está estabilizado. A agropecuária contribui com aproximadamente $0,2 \%$ do PIB do DF, enquanto o setor de serviços é responsável por mais de $81 \%$ do total (IBGE, 2008).

Antes da instituição do Programa Nacional de Controle e Erradicação da Brucelose e Tuberculose Animal (PNCEBT), o controle da brucelose bovina, no Brasil, era regulamentado pelas Normas para a Profilaxia da Brucelose Animal (Brasil, 1976), cuja eficácia era baixa. O Distrito Federal nunca teve um programa próprio de combate à brucelose bovina e a real situação epidemiológica da doença não é adequadamente conhecida. O presente estudo teve por objetivos estimar a prevalência, identificar os fatores de risco para a brucelose bovina no DF e fornecer subsídios para a gestão estratégica do PNCEBT.

\section{MATERIAL E MÉTODOS}

O estudo foi planejado por técnicos do Ministério da Agricultura, Pecuária e Abastecimento, da Universidade de São Paulo e da Universidade de Brasília, em colaboração com técnicos da SEAP. O trabalho de campo foi realizado por técnicos das regionais administrativas da SEAP, no período de fevereiro a dezembro de 2003.

Em virtude da área territorial e da pecuária pouco expressiva do Distrito Federal, considerou-se que os sistemas de produção bovina, práticas de manejo, finalidades de exploração, tamanho médio de rebanhos e sistemas de comercialização seriam homogêneos em toda a população-alvo, não sendo necessário proceder à estratificação regional da amostra. Foi estimada a prevalência de propriedades infectadas pela brucelose bovina e a de animais soropositivos por meio de um estudo amostral em dois estágios, com o fim de detectar focos da doença no DF. No primeiro estágio foram sorteadas, de forma aleatória, um número pré-estabelecido de propriedades com atividade reprodutiva (unidades primárias de amostragem). No segundo, em cada propriedade, foi sorteado um número pré-estabelecido de fêmeas bovinas com idade igual ou superior a 24 meses (unidades secundárias de amostragem).

Nas propriedades rurais onde existia mais de um rebanho, foi escolhido o rebanho bovino de maior importância econômica, no qual os animais estavam submetidos ao mesmo manejo, ou seja, sob as mesmas condições de risco. A escolha da unidade primária de amostragem foi aleatória sistemática, baseada no cadastro de propriedades rurais com atividade reprodutiva de bovinos. A propriedade sorteada que, por motivos vários, não pôde ser visitada, foi substituída por outra, nas proximidades, com as mesmas características de produção. $\mathrm{O}$ número de propriedades selecionadas foi estimado pela fórmula, para amostras simples aleatórias, proposta por Thrusfield (2007). Os parâmetros adotados para o cálculo foram: nível de confiança de 0,95 , prevalência estimada de 0,25 e erro de 0,05 . A capacidade operacional e financeira do serviço veterinário oficial do DF também foi levada em consideração para a determinação do tamanho da amostra. Foram amostradas 278 propriedades, distribuídas da seguinte forma pelas unidades administrativas da Secretaria de Estado de Agricultura e Pecuária (SEAP): 62 propriedades na área administrativa do Gama, 57 em Planaltina, 44 em Rio Preto, 57 em Brazlândia e 58 em Sobradinho.

O planejamento amostral para as unidades secundárias visou estimar um número mínimo de animais a serem examinados dentro de cada propriedade de forma a permitir a sua classificação como foco ou não foco de brucelose. Para tanto, foi utilizado o conceito de sensibilidade e especificidade agregadas (Dohoo et al., 2003). Para efeito dos cálculos foram adotados os valores de $95 \%$ e $99,5 \%$, respectivamente, para a sensibilidade e a especificidade do protocolo de testes utilizado (Fletcher et al., 1988) e 20\% para a prevalência intra-rebanho estimada. Nesse processo foi utilizado o programa Herdacc versão 3 e o tamanho da amostra escolhido foi aquele que permitiu valores de sensibilidade e especificidade de rebanho iguais ou superiores a 


\section{Gonçalves et al.}

90\%. Assim, nas propriedades com até 99 fêmeas com idade superior a 24 meses, foram amostrados 10 animais e nas com 100 ou mais fêmeas com idade superior a 24 meses, 15 animais. A escolha das fêmeas dentro das propriedades foi aleatória sistemática.

O protocolo de testes de sorodiagnóstico foi composto pela triagem com o teste do antígeno acidificado tamponado (Rosa Bengala), seguida do reteste dos positivos com o teste do 2mercaptoetanol, de acordo com as normas do PNCEBT (Brasil, 2006). O sangue foi coletado por punção da veia coccígea com agulha descartável estéril em tubo com vácuo, previamente identificado. Os soros, armazenados em microtubos de plástico, foram mantidos a $20^{\circ} \mathrm{C}$ até a realização dos testes. A triagem com o teste do antígeno acidificado tamponado foi realizado no Laboratório da SEAP, e o reteste dos positivos pelo 2-ME no Departamento de Patologia da Universidade Federal de Goiás.
A propriedade foi considerada positiva quando se detectou pelo menos um animal positivo. As propriedades que apresentaram animais com resultado sorológico inconclusivo, sem animal positivo, foram classificadas como suspeitas e excluídas das análises. $\mathrm{O}$ mesmo tratamento foi dado aos animais com resultados sorológicos inconclusivos.

O planejamento amostral permitiu determinar as prevalências de focos e de fêmeas adultas ( $\geq 24 \mathrm{~m}$ ) soropositivas para brucelose no DF. Os cálculos das prevalências aparentes e os respectivos intervalos de confiança foram realizados conforme preconizado por Dean et al. (1994).

O cálculo da prevalência de animais foi feito de forma ponderada, conforme preconizado por Dohoo et al. (2003). O peso $(P)$ de cada animal no cálculo da prevalência de animais foi dado por

$P=\frac{\text { fêmeas } \geq 24 \text { meses na propriedade }}{\text { fêmeas } \geq 24 \text { meses amostradas na propriedade }} \times \frac{\text { fêmeas } \geq 24 \text { meses na região }}{\text { fêmeas } \geq 24 \text { meses nas propriedades amostradas na região }}$

Na expressão, o primeiro termo refere-se ao peso de cada animal no cálculo da prevalência de animais na região.

Em cada propriedade amostrada, além da coleta de sangue para a sorologia, foi também aplicado um questionário epidemiológico, elaborado para obter informações sobre o tipo de exploração e as práticas de manejo empregadas.

Todas as informações geradas pelo trabalho de campo e de laboratório foram inseridas em um banco de dados específico, utilizado nas análises epidemiológicas.

\section{RESULTADOS E DISCUSSÃO}

Na Fig. 1, encontra-se a distribuição espacial das propriedades sorteadas aleatoriamente. Os dados censitários, tomados como base para os cálculos da amostra e das prevalências, foram os mais atualizados e disponíveis à época do trabalho de campo, no ano de 2003. A Tab. 1 traz um resumo desses dados censitários fornecidos pela SEAP do Distrito Federal.

$\mathrm{Na}$ Tab. 2, são apresentados os resultados de prevalência de focos no DF. A prevalência de focos por tipo de exploração da propriedade é apresentada na Tab. 3 e a prevalência de animais na Tab. 4.

No DF, a prevalência estimada de focos e de fêmeas soropositivas foi baixa. O limite superior do intervalo de confiança de $95 \%$ não ultrapassou 5,1\% para focos e $0,28 \%$ para animais. Entre as 278 propriedades amostradas, foram encontradas apenas sete positivas e nestas foi observado apenas um animal soropositivo por foco. Dos sete focos, três são propriedades de leite e quatro são de aptidão mista. 


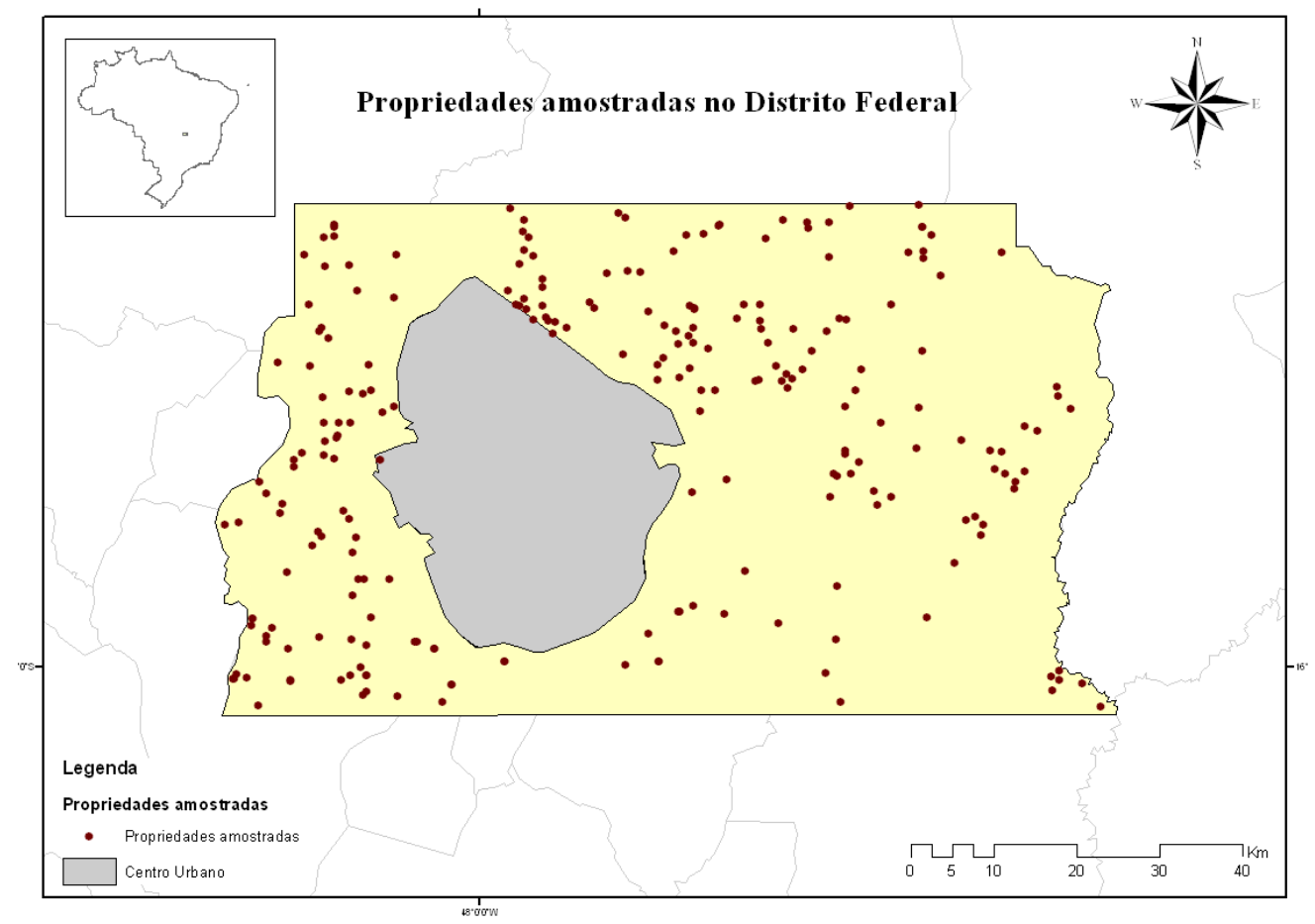

Figura 1. Mapa do Distrito Federal representando a localização das propriedades amostradas.

Tabela 1. Dados censitários da população bovina do Distrito Federal em 2003

\begin{tabular}{cccc}
\hline $\begin{array}{l}\text { Total de propriedades } \\
\text { com atividade reprodutiva }\end{array}$ & $\begin{array}{l}\text { Propriedades } \\
\text { amostradas }\end{array}$ & $\begin{array}{l}\text { Total de fêmeas } \\
\text { com idade } \geq 24 \text { meses }\end{array}$ & $\begin{array}{c}\text { Fêmeas } \\
\text { amostradas }\end{array}$ \\
\hline 3.314 & 278 & 38.040 & 2.019 \\
\hline
\end{tabular}

Tabela 2. Prevalência de focos de brucelose no Distrito Federal

\begin{tabular}{|c|c|c|c|}
\hline \multicolumn{2}{|c|}{ Propriedades } & \multirow{2}{*}{ Prevalência (\%) } & \multirow{2}{*}{ IC (95\%) } \\
\hline Testadas & Positivas & & \\
\hline 278 & 7 & 2,52 & {$[1,02-5,12]$} \\
\hline
\end{tabular}

Tabela 3. Prevalência (Prev) de focos de brucelose bovina estratificada por tipo de exploração no Distrito Federal

\begin{tabular}{cccccccc}
\hline \multicolumn{3}{c}{ Corte } & & \multicolumn{2}{c}{ Leite } & & \multicolumn{2}{c}{ Misto } \\
\cline { 1 - 2 } Prev (\%) & IC (95\%) & & Prev (\%) & IC (95\%) & & Prev (\%) & IC (95\%) \\
0,0 & {$[0,00-14,82]$} & & 2,50 & {$[0,52-7,13]$} & & 2,22 & {$[0,46-6,36]$} \\
\hline
\end{tabular}

IC: intervalo de confiança.

Tabela 4. Prevalência de bovinos sororreagentes para brucelose no Distrito Federal

\begin{tabular}{|c|c|c|c|}
\hline \multicolumn{2}{|c|}{ Animais } & \multirow{2}{*}{$\begin{array}{c}\text { Prevalência } \\
(\%)\end{array}$} & \multirow{2}{*}{ IC (95\%) } \\
\hline Testados & Positivos & & \\
\hline 2.019 & 7 & 0,16 & {$[0,04-0,28]$} \\
\hline
\end{tabular}


Este diagnóstico de situação coloca o DF numa posição privilegiada para adotar plenamente as estratégias sanitárias preconizadas pelo PNCEBT (Brasil, 2006). As autoridades sanitárias e o setor produtivo poderão iniciar projetos de certificação de propriedades livres de brucelose, sabendo-se que a prevalência será baixa, assim como o número de animais a serem sacrificados. No entanto, a predominância de rebanhos pequenos e pouco tecnificados pode ser um obstáculo à rápida adesão dos pecuaristas a um programa de certificação voluntária. Assim, o PNCEBT no DF deve procurar desenvolver e consolidar um sistema de vigilância de brucelose (Crawford et al., 1990; Acha e Szyfres, 2001; Paulin e Ferreira Neto, 2003) que permita detectar os focos existentes, com boa sensibilidade e baixo custo. Com este propósito, os laticínios devem ser parceiros do Programa, dado que a realização sistemática do teste do anel em leite (Brasil, 2006) ajudará a atingir esse objetivo, complementando a realização periódica de testes sorológicos. Se a identificação de propriedades suspeitas no teste do anel em leite gerar uma investigação epidemiológica que resulte na erradicação do(s) foco(s) e posterior certificação dos rebanhos, o DF poderá caminhar para a situação em que o risco de brucelose será desprezível.

A prevalência estimada obriga também a pensar na estratégia de vacinação obrigatória de bezerras. É provável que mesmo uma boa cobertura vacinal não contribua para baixar significativamente uma prevalência tão baixa. No entanto, o risco de introdução de bovinos infectados no DF é grande, dada a interdependência com o Estado de Goiás, ou mesmo com Minas Gerais. Neste contexto, a vacinação pode ser um instrumento eficaz para garantir que as fontes de infecção que ingressarem no DF não encontrarão animais suscetíveis em número suficiente, prevenindo assim a disseminação da doença entre os rebanhos. Porém, se a vigilância da doença e a realização sistemática de testes diagnósticos forem intensificadas e sustentadas, com eliminação das fontes de infecção, a vacinação de bezerras poderá tornar-se obsoleta. Cabe às autoridades sanitárias e aos pecuaristas do DF decidir se querem manter a prevalência da doença em níveis baixos e sob controle ou se pretendem avançar para a erradicação da brucelose.

\section{AGRADECIMENTOS}

À FAPESP, ao CNPq, à SEAP-DF e ao MAPA pelo apoio financeiro.

\section{REFERÊNCIAS BIBLIOGRÁFICAS}

ACHA, P.N.; SZYFRES, B. Zoonosis y enfermedades transmisibles comunes al hombre y a los animales: Bacterioses e micoses. 3.ed. Washington: OPAS, 2001. 416p.

BRASIL. Ministério da Agricultura, do Abastecimento e da Reforma Agrária. Portaria no. 23/76, de 20 de janeiro de 1976: Manual de procedimentos. Movimentação interestadual de animais e produtos. 5.ed. Diário Oficial da União, Brasília, 16 de fev.1976. Seção I, pt.I, p.2266-2269.

BRASIL. Ministério da Agricultura, Pecuária e Abastecimento. Programa Nacional de Controle e Erradicação da Brucelose e da Tuberculose Animal (PNCEBT): Manual técnico. Ministério da Agricultura, Pecuária e Abastecimento, Brasília, 2006. 184p.

CRAWFORD, R.P.; HUBER, J.D.; ADAMS, B.S. Epidemiology and surveillance. In: NIELSEN, K.; DUNCAN, J.R. (Ed.). Animal brucellosis. Boca Raton: CRC Press, 1990. p.131-151.

DEAN, A.G.; DEAN, J.A.; COLOMBIER, D. et al. Epi-Info, version 6: A word processing database and statistics program for epidemiology on microcomputers. Atlanta: CDC, 1994. 601p.

DOHOO, I.; MARTIN, W.; STRYHN, H. Veterinary epidemiologic research. Charlottetown, Canadá: Atlantic Veterinary College, 2003. 706p.

FLETCHER, R.H.; FLETCHER, S.W.; WAGNER, E.H. Clinical epidemiology: The essentials. 2.ed. Baltimore: Williams \& Wilkins, 1998. 246p.

IBGE. Rio de Janeiro, 2008. Disponível em: http:www.sidra.ibge.gov.br. Acessado em: abr. 2008.

PAULIN, L.M.; FERREIRA NETO, J.S. $O$ combate à brucelose bovina: Situação brasileira. Jaboticabal: Funep, 2003. 154p.

THRUSFIELD, M. Veterinary epidemiology. 3.ed. Oxford: Blackwell Science, 2007. 610p. 